\title{
Ensinar área de quadriláteros regulares baseado no modelo de Van Hiele
}

Teach quads scheduled area based on Van Hiele model

Thiago Beirigo Lopes ${ }^{1}$

Ritianne de Fatima Silva de Oliveira ${ }^{2}$

Ademir Brandão Costa ${ }^{3}$

Marcelo Franco Leão ${ }^{4}$

\section{Resumo}

Esse estudo utilizou a metodologia de Van Hiele com os cinco níveis hierárquicos e cinco fases de aprendizagem que devem integrar cada nível. Optou-se pelo cálculo de áreas de quadriláteros regulares devido serem formas geométricas simples e de muitas aplicações. O objetivo foi verificar se essa metodologia favorece a compreensão de áreas de quadriláteros aos 25 estudantes da $4^{\underline{a}}$ etapa de Educação de Jovens e Adultos (EJA) em uma escola pública em Canaã dos Carajás/PA. Essa turma possui dispersão significativa em relação à idade, que é um dos fortes argumentos do uso do método de Van Hiele. Foram elaborados o pré-teste e pós-teste aliados à duas intervenções pedagógicas que trabalham a utilização de malhas quadriculadas em papel e embalagens comuns no cotidiano. O intuito foi comparar o nível de compreensão dos estudantes antes e depois do emprego da metodologia. Ocorreu um aumento significativo no número de acertos comparando o pós teste com o pré-teste. Por tais resultados, fica evidente a necessidade de desenvolvermos o ensino de geometria que possibilite aos alunos serem protagonistas e participarem ativamente da construção de seus saberes, em especial os refere ao cálculo de áreas de quadrilátero regulares.

Palavras-chave: Geometria. Van Hiele. Metodologia. Educação Matemática.

\section{Introdução}

$O$ ato de ensinar matemática nunca foi simples, pois exige do professor, além do domínio sobre os saberes a ensinar, a demanda de muito tempo para leitura, planejamento, metodologia e recursos didáticos. Para tanto, devido o

\footnotetext{
${ }^{1}$ Mestre, professor, Instituto Federal de Mato Grosso, thiagobeirigolopes@yahoo.com.br

${ }^{2}$ Especialista, professora, Secretaria Municipal de Educação de Canaã dos Carajás/PA, ritianne19@hotmail.com

${ }^{3}$ Especialista, professor, Secretaria Municipal de Educação de Canaã dos Carajás/PA, ademirbrandao@gmail.com

${ }^{4}$ Mestre, professor, Instituto Federal de Mato Grosso, marcelo.leao@cfs.ffmt.edu.br
} 
momento de revolução tecnológica que seduz os estudantes com uma cultura do imediatismo, $\mathrm{o}$ ato de ensinar tem se tornado uma tarefa demasiadamente complexa e desafiadora.

Perante essas inovações na tecnologia, a escola tem se tornado um espaço de intenso conflito. Em um extremo, ficam os professores fadigados na tentativa de convencer o estudante sobre a importância de se estudar Matemática e abordar os tópicos do currículo escolar, no outro, os que apresentam uma postura alheia e apática ao processo de ensino, por atendê-lo como monótono e inútil no seu cotidiano.

Nessa conjuntura educacional atual, é preciso considerar que os estudantes possuem particularidades nos ritmos e maneiras para aprender (MATOS e SERRAZINA, 1996). Em se tratando de educação matemática, um dos assuntos em pauta nas discussões está relacionado a construção dos conceitos geométricos. Para essa construção, a teoria de Van Hiele nasce com o objetivo de favorecer ao professor a identificação destas particularidades apresentadas por eles e provê uma alternativa de intervenção para solidificar a compreensão de tais assuntos.

Outro fator importante da teoria, talvez o mais importante, é a participação ativa do estudante na construção do seu próprio conhecimento, tendo assim uma alternativa ao defasado modelo de aula predominantemente expositiva ainda presente em nossas escolas (LORENZATO, 2009).

Nesse contexto, o modelo proposto por Van Hiele vem contribuir de forma bastante significativa para o ensino de geometria nas séries finais no Ensino Fundamental. Seu principal objetivo é promover uma aprendizagem significativa, nos moldes defendidos por Ausubel (2003), para o estudo dos cálculos de área dos quadriláteros regulares. Tentando assim, resgatar a atenção dos estudantes que hoje estão tão multiconectados.

Diante do exposto, o objetivo desse estudo foi o de promover a autonomia do estudante na construção do conhecimento geométrico de maneira a proporcionar o aprendizado significativo sobre áreas de quadriláteros regulares, 
fazendo dele um ativo participativo na construção de conceitos matemáticos, valendo-se de linguagem apropriada e materiais concretos. Dessa maneira, a proposta é comparar a compreensão dos estudantes antes e depois dessa experiência pedagógica por meio de pré e pós-teste.

Vale lembrar que o modelo de Van Hiele pode ser trabalhado tanto com materiais físicos palpáveis como com materiais não-físicos utilizando-se das novas tecnologias aplicadas no ensino. Embasando-nos nessa metodologia proporemos um material didático, a partir do qual, o professor possa fazer o uso de tecnologias e atividades em que o estudante possa fazer parte ativa do processo de sua própria aprendizagem.

\section{Princípios básicos do método de Van Hiele}

O foco desse método é que os estudantes progridam de acordo com uma sequência de níveis de compreensão de conceitos, enquanto eles aprendem geometria (NASSER e SANT'ANNA, 2010). Para que avance de um nível para outro, o professor necessitará produzir ou selecionar uma sequência de atividades que beneficie a aprendizagem dos conceitos geométrico. Desse modo, fica tácito no método de Van Hiele que o desenvolvimento depende mais da adequação das atividades, do que da maturação do estudante, o que a distingue de outros métodos didáticos existentes.

\subsection{0 modelo proposto pelos Van Hiele}

O modelo de Van Hiele viabiliza avaliar, através das habilidades comprovadas, o nível cognitivo geométrico de um estudante em um conteúdo específico de geometria. Lorenzato (2009), referindo-se a esse modelo, destaca que respeitar a sequência didática significa não saltar etapas ou níveis no ensino.

É estabelecido no modelo de Van Hiele cinco níveis hierárquicos para aprendizagem de conceitos, no sentido que o estudante só atinge o nível de 
raciocínio seguinte após dominar os níveis atual e anteriores. Talvez esteja neste fato o cerne da questão do porquê alguns apresentarem maiores dificuldades na aprendizagem num curso de geometria embasado em demonstrações lógicodedutivas, sem terem vivenciado os níveis anteriores. Segue uma breve descrição de cada nível (CROWLEY, 1994):

Nível 0 (Reconhecimento): Reconhecimento, comparação e nomenclatura das figuras geométricas por sua aparência global.

Nível 1 (Análise): Análise das figuras em termos de seus componentes, reconhecimento de suas propriedades e uso dessas propriedades para resolver problemas.

Nível 2 (Dedução informal ou abstração): Percepção da necessidade de uma definição precisa, e de que uma propriedade possa decorrer de outra, argumentação lógica informal e ordenação de classes de figuras geométricas.

Nível 3 (Dedução): Domínio do processo dedutivo e das demonstrações, reconhecimento de condições necessárias e suficientes.

Nível 4 (Rigor): Capacidade de compreender demonstrações formais; Estabelecimento de teoremas em diversos sistemas e comparação dos mesmos.

\subsection{O papel do professor no método de Van Hiele}

Por meio desse método, cabe ao professor elaborar ou organizar minuciosamente uma sequência didática que contemple o progresso do estudante de um nível para o posterior na aprendizagem de um determinado conceito geométrico é o seu principal papel, segundo o método de Van Hiele. Para tanto, o propuseram cinco fases sequenciais de aprendizagem onde se propicia o acesso para o nível seguinte. Uma breve descrição de cada fase é exposta a seguir (CROWLEY, 1994; NASSER e SANT'ANNA, 2010):

Fase 1 (Interrogação/Informação): Diálogo entre o professor e estudantes, na proposta de desenvolverem atividades englobando os objetos de estudo do 
referente nível. O objetivo principal nessa fase é fazer uma pesquisa prévia dos conhecimentos e promover nos mesmos os conceitos a serem desenvolvidos.

Fase 2 (Orientação dirigida): Os estudantes realizam uma sequência de atividades didáticas elaboradas minuciosamente pelo professor a respeito do conceito a ser desenvolvido neste nível. Essa sequência deve possuir um nível gradual de dificuldade composto por pequenas tarefas a serem executadas para responder a questões específicas sobre o tópico.

Fase 3 (Explicação): O papel do professor é reduzido e os estudantes socializam os resultados obtidos pelo cumprimento das atividades antes desenvolvidas. Por meio da comparação das respostas, começa-se a reelaborar as estruturas prévias e, por conseguinte, aprimoram seus conceitos sobre 0 conteúdo em estudo.

Fase 4 (Orientação livre): Os estudantes ficam diante de desafios que exigem diversas etapas para serem concluídos. As tarefas devem ser complexas, possuírem diversas formas de serem executadas ou até mesmo terem final aberto.

Fase 5 (Integração): Os estudantes fazem uma síntese, junto ao professor, sobre os resultados adquiridos no nível e edificam um novo circuito de objetos e relações. Tendo o cuidado para não introduzir conhecimento novo fora da descoberta deles próprios.

Van Hiele afirma que, concretizando adequadamente a sequência de fases, o estudante terá desenvolvido um conhecimento novo, suprindo o antigo e avançando de nível, fazendo que o professor recomece o trabalho no novo nível (CROWLEY, 1994; NASSER e SANT'ANNA, 2010).

\section{Procedimentos metodológicos}

Este estudo foi realizado com o uso da pesquisa exploratória, que segundo Gil (2002) tem o objetivo de esclarecer as ideias que são desenvolvidas de modo a oferecer uma maior intimidade com o problema, para melhor evidenciá-lo, 
edificando uma vista geral sobre determinado fato, englobando levantamento bibliográfico, testes e análise de exemplos que ajudem sua compreensão.

A pesquisa exploratória é usada quando o pesquisador se encontra diante de temas pouco estudados, o que dificulta a formulação de hipóteses precisas, adotando, geralmente, as formas de pesquisas bibliográficas e estudos de caso. Sendo obtidos resultados quantitativos por meio dos testes realizados e explorando qualitativamente o comportamento e atitudes dos estudantes que foram percebidos pelos pesquisadores.

Partindo do pressuposto que, "a escolha dos informantes ou sujeitos do estudo deve ser baseada na procura por indivíduos sociais que tenham uma vinculação significativa com o objeto de estudo" (NEVES e DOMINGUES, 2007, p. 57), os testes e a intervenção pedagógica sugeridos nesse estudo foram aplicados aos 25 estudantes da $4^{\text {a }}$ etapa de EJA, já que o tema de área de quadriláteros regulares é parte que integra o currículo mínimo para este ano de escolaridade.

O local de aplicação foi em uma escola pública situada na cidade de Canaã dos Carajás no estado do Pará. Optamos por uma escola da rede pública devido aos fatores sociais, econômicos e organizacionais que estão envolvidos na aprendizagem da Geometria.

Essa intervenção contou com a colaboração de uma professora, que também é autora desse trabalho, que já é efetiva na turma escolhida para a realização desse projeto, se dispondo a colaborar com seus depoimentos e experiências. Essa turma foi selecionada para aplicar nossa proposta de metodologia por ser uma turma onde há uma heterogeneidade devido reunir vários contextos sociais e uma dispersão em relação à idade que é um dos fortes argumentos do uso do modelo de Van Hiele.

Na primeira aula, a professora utilizou o teste dos níveis de Van Hiele que foi elaborado por Nasser e Sant'anna (2010) e que também foi utilizado por Souza (2014), em seus estudos. Esse teste possui 15 questões distribuídas em três 
grupos, sendo cada um deles correspondente a um dos níveis de Van Hiele. Seu objetivo foi averiguar o nível de conhecimento geométrico de cada estudante.

O primeiro grupo de questões (nível 0) caracteriza-se pela competência de identificação, comparação e nomenclatura de figuras geométricas planas baseando-se em sua aparência global. O segundo grupo de questões (nível 1) tem como característica a análise dos componentes de uma figura geométrica, a consideração de suas propriedades e a utilização dessas propriedades para resolver problemas. O terceiro grupo de questões (nível 2) caracteriza-se pelas competências de percepção da necessidade de uma definição precisa, percepção de que uma propriedade pode derivar de outra; argumentação lógica informal e ordenação de classes de figuras geométricas. Nessa experiência tivemos estudantes que não se enquadraram em algum dos 3 níveis citando, sendo classificados como 'sem nível' ${ }^{5}$ os que não conseguiam sequer identificar as figuras geométricas planas básicas.

$\mathrm{Na}$ segunda aula utilizou-se um instrumento valioso para responder à pergunta da pesquisa, que foi um teste contendo 10 questões sobre áreas de quadriláteros regulares, que denominaremos inicialmente de pré-teste. Esse mesmo teste foi aplicado também ao final da realização das atividades, que denominaremos de pós-teste. Esse instrumento foi elaborado pelos pesquisadores para comprovar se, de fato, as atividades propostas e realizadas contribuíram para a aprendizagem do conteúdo Áreas de Quadriláteros Regulares. Segue as questões utilizadas desse instrumento de coleta de dados.

Figura 1 - Questão 1 do pré e pós-teste

1) Para você, o que é área de uma figura?

Fonte: Da pesquisa.

O intuito ao perguntar "O que é área de uma figura?" na primeira questão desse instrumento foi analisar sobre a conceitualização de área, ou seja, o conhecimento prévio dos estudantes no pré-teste e a elaboração conceitual após

\footnotetext{
${ }^{5}$ Tal classificação teve de ser criada, pois na Teoria de Van Hiele não há uma definição ou classificação para os que não possuem sequer os conhecimentos geométricos necessários para serem enquadrados no nível 0 .
} 
o aprendizado (pós-teste). Já a questão 2 (Figura 2) tem por objetivo, analisar se conseguem visualizar a área como a composição de quadradinhos de lado unitário. Esta questão é importante pelo fato de auxiliar na compreensão e conceitualização de áreas de quadriláteros.

Figura 2 - Questão 2 do pré e pós-teste

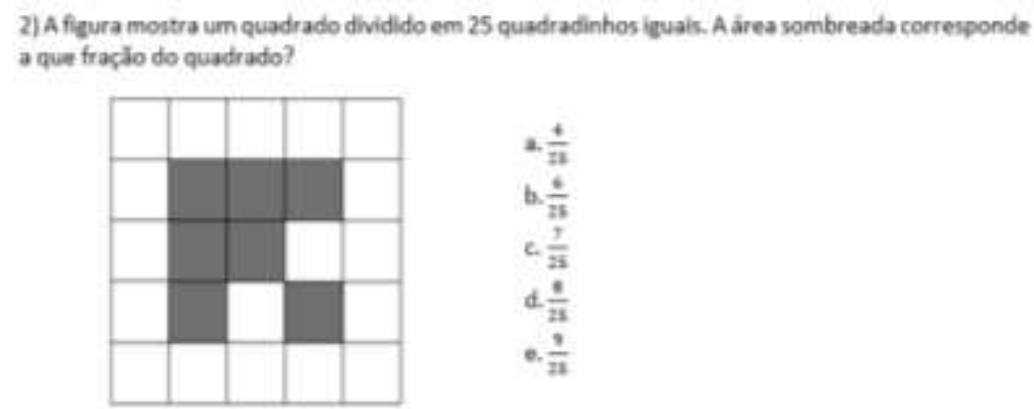

Fonte: Da pesquisa.

$\mathrm{Na}$ questão 3 (Figura 3), além de indicar a área de quadriláteros como um agrupamento de quadradinhos de lado unitário com na questão anterior, é possível perceber o aditamento de área como uma concepção que não depende de sua forma, ou seja, compreender que figuras com formas distintas podem ter a mesma área.

Figura 3 - Questão 3 do pré e pós-teste

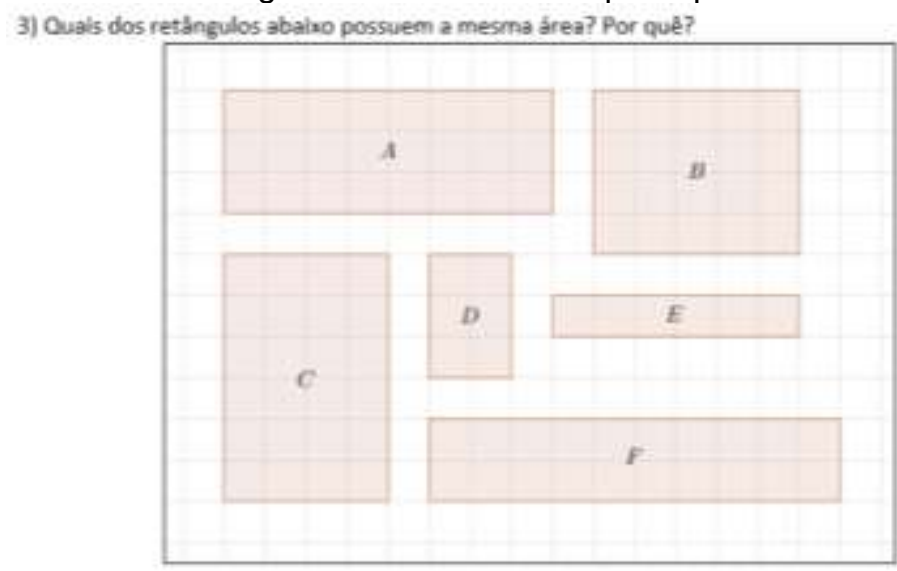

Fonte: Da pesquisa.

A questão 4 (Figura 4) visa verificar se há a capacidade de perceber a área de figuras em como composição de quadrados sem que estes estejam bem definidos na figura. Também é pretendido verificar se o estudante consegue fazer 
uma estimativa de uma figura toda tendo que se embasar somente em um quadradinho destacado, que nesse caso está no lado inferior direito.

Figura 4 - Questão 4 do pré e pós-teste

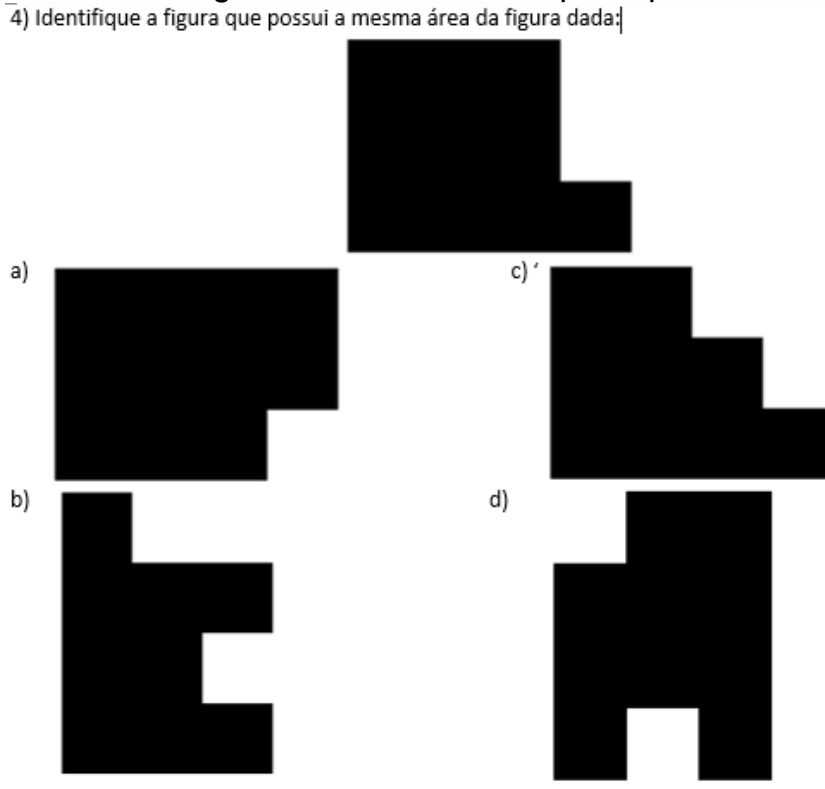

Fonte: Da pesquisa.

Com a questão 5 (Figura 5) é possível verificar se o aprendiz possui a competência de contabilizar a quantidade desses quadradinhos com a ajuda de uma malha quadriculada para a concepção da área da figura em cinza, além de perceber a área de figuras de lados paralelos e perpendiculares como agrupamento de quadradinhos.

Figura 5 - Questão 5 do pré e pós-teste

5) Considerando o quadradinho menor como unidade de área, calcule a área das figuras abaixo:

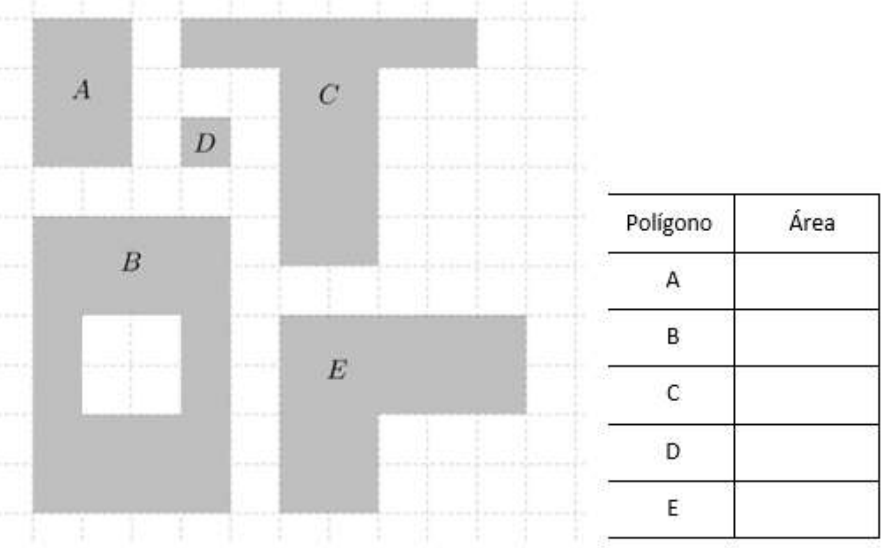

Fonte: Da pesquisa. 
Já na questão 6 (Figura 6) buscou-se verificar o raciocínio abstrato já adquirido pelo estudante derivado das propriedades dos quadriláteros e sua área. Assim, observa-se o nível de conhecimento formal que o aprendiz já possui sobre o objeto de estudo.

Figura 6 - Questão 6 do pré e pós-teste

6) Marque $X$ para as afirmativas verdadeiras:

A)( )Todo quadrado é um retângulo.

B)( )Todo retângulo é um quadrado.

C)( )A área do quadrado é a multiplicação da base pela altura.

D)( )A área do retângulo é a multiplicação da base pela altura.

E)( A área do triângulo é a metade da base multiplicada pela altura.

F)( )A área do quadrado é o valor do lado elevado a dois.

G)( )A área do retângulo é a metade da base multiplicada pela altura.

H)( ) A área do triângulo é a metade da área do retângulo de mesma base e altura.

Fonte: Da pesquisa.

E nas questões finais, respectivamente 7, 8, 9 e 10 na Figura 7, pretendemos analisar no pré-teste sobre a aplicação na realidade em relação aos conhecimentos que possuem e, no pós-teste, sobre os adquiridos.

Figura 7 - Questões 7, 8, 9 e 10 do pré e pós-teste

7) Uma caixa de sapatos tem a forma de um paralelepípedo retângulo e dimensões iguais a $10 \mathrm{~cm}$, $15 \mathrm{~cm}$ e $20 \mathrm{~cm}$. Quantos centímetros quadrados de papelão são necessários para se construir essa caixa? Admita que se utilize $10 \%$ a mais de material para que seja possível fazer colagens e dobraduras necessárias à confecção da caixa.

8) Uma caixa em formato retangular tem dimensões, $15 \mathrm{~cm}, 30 \mathrm{~cm}$ e $20 \mathrm{~cm}$, calcule a área total dessa caixa.
(A) 2500
(B) 2600
(C) 2700
(D) 3600

9) Deseja ladrilhar uma cozinhas nas seguintes condições: 5 metros de comprimento, 4 metros de largura, 2,5 metros de altura e as portas e janelas ocupam uma área de $3 \mathrm{~m}^{2}$. Calcule a metragem quadrada de ladrilhos que se deve comprar.

10) Um arquiteto tem dois projetos para construção de uma piscina retangular com $2 \mathrm{~m}$ de profundidade:

- Projeto 1: dimensões do retângulo: $15 \mathrm{~m} \times 15 \mathrm{~m}$

- Projeto 2: dimensões do retângulo: $10 \mathrm{~m} \times 20 \mathrm{~m}$.

Qual dos dois projetos fica mais economicamente viável para o proprietário da piscina?

Fonte: Da pesquisa.

Além dos testes supracitados, propôs-se nas aulas seguintes uma intervenção pedagógica por meio da aplicação de 2 atividades sobre áreas, focando o uso de materiais manipuláveis e tecnologias, seguindo as fases de aprendizagem segundo a Teoria de Van Hiele. Ainda entendemos que se deve trabalhar por meio de situações problema, pois temos ciência "[...] da importância 
do ensinar por situações problemas, e da flexibilidade no planejamento como forma de atender e perceber as necessidades e dificuldades que estes sujeitos em aprendizagem têm sobre determinados conceitos, e dessa forma, respeitá-los como legítimos na convivência" (MORAES, GAUTÉRIO, et al., 2015, p. 162).

Sendo a primeira atividade orientada para a percepção das figuras geométricas no plano por meio de uma malha quadriculada impressa e a segunda atividade sendo orientada para o cálculo de áreas de superfícies de sólidos geométricos que vemos no nosso cotidiano através de atividades envolvendo embalagens de produtos que encontramos em casa, como caixa de leite, de fósforos, de bombons, entre outras muitas embalagens.

O foco principal dessa intervenção pedagógica é propiciar o desenvolvimento de competências e habilidades, gerando o avanço no que diz respeito ao conhecimento geométrico dos sujeitos da pesquisa. Todas as atividades foram elaboradas e executadas de acordo com as fases de aprendizagem da Teoria de Van Hiele.

Nessa experiência realizamos cinco atividades, conforme as fases indicadas por Van Hiele, no período de 2 aulas semanais, durante 3 semanais, por atividade:

Fase 1 (Interrogação/Informação): Atividades com figuras e imagens expostas pela professora seguidas das indagações: Quais são os polígonos das faces? O que é um retângulo? O que é um paralelogramo?

A primeira etapa consistiu em expor figuras bidimensionais e tridimensionais para que os estudantes reconhecessem conceitos sobre os quadriláteros. A análise desses resultados indica o grau de dificuldade deles em escrever tais conceitos, pois todos relataram que não entenderam como realizar a tarefa. Diante desta situação a professora teve que realizar uma breve revisão de conceitos geométricos básicos por meio de perguntas de modo que tentassem relembrar o que haviam aprendido até aquele momento.

Fase 2 (Orientação Dirigida): Atividades com a Malha Quadriculada. 
Nessa etapa, o objetivo foi explorar as características dos quadriláteros através dos desenhos dessas figuras planas na malha quadriculada, impressa em papel, realizados pelos estudantes. A professora dirigiu a atividade indicando que desenho eles teriam que representar na malha, ainda solicitando que fossem feitos quadriláteros com áreas específicas. Ao final da atividade, com a interferência da professora, foi realizado a explicação dos conceitos matemáticos, características e diferenças entre os quadriláteros.

Fase 3 (Explicação): Demonstração da área do retângulo no quadro negro.

Nessa terceira etapa, o objetivo foi o de explicar e explorar as dúvidas e questionamentos que havia, surgiram dúvidas quanto ao tamanho de ângulos de quadriláteros, os tipos de quadriláteros, diferenças e semelhanças entre retângulos e quadrados, entre outros. Assim, a professora foi registrando as situações no quadro e, posteriormente, socializando os resultados e conclusões encontradas. A partir desta ação, cada estudante contribuiu com o seu relato e juntos esclareceram suas dúvidas e compartilharam o processo desenvolvido entre eles.

Fase 4 (Orientação Livre): Cálculo de superfície de embalagens de produtos utilizados em casa.

$\mathrm{Na}$ etapa quatro, o objeto foi o de perceber o conteúdo estudado à sua volta, sendo uma atividade onde o estudante calculou áreas de figuras de seu interesse. Para tanto se fez uso das embalagens de produtos encontrados em casa como modelo alternativo e concreto para abordagem do conteúdo. Sendo solicitado o cálculo da área das superfícies que compõem o exterior das embalagens.

Fase 5 (Integração): Organização de um cartaz com as fórmulas de área dos principais polígonos trabalhadas.

Nessa última etapa, o objetivo foi o de construir e sistematizar o que foi aprendido nas atividades anteriores. Para isto, os estudantes elaboraram cartazes com desenhos explicativos e fórmulas para eu fossem fixados nas paredes da sala de aula. 
Como enfatizado anteriormente, o avanço ao longo dos níveis está intrinsicamente ligado mais da instrução recebida do que da idade do estudante. O modelo de aprendizagem desenvolvido pelos Van Hiele, além de diagnosticar o nível de maturidade geométrica dos estudantes, ainda mostram meios para auxiliá-los a avançar de um nível para o seguinte, sendo o ensino o principal fator que contribui para esse desenvolvimento (CROWLEY, 1994).

Para as intervenções pedagógicas utilizamos primeiramente a malha quadriculada em papel A4, para atividades que permitam os estudantes perceberem as áreas de quadriláteros como a junção de pequenos quadrados de lado de tamanho unitário. Posteriormente fizemos uso de estudo das áreas de embalagem que são formadas por retângulos, como caixa de bombom, leite e sapato. Desse modo pretendemos que os estudantes tenham contato do que seja o objeto de estudo, que são as áreas. Pois além de saberem o conceito de área de quadriláteros regulares, que sintam através do seu tato o que significa essa atividade.

Finalizando esse momento diretamente com os estudantes, houve a aplicação do pós-teste para preceder com a comparação de resultados obtidos e verificação da eficácia da proposta de atividade baseada no modelo de Van Hiele.

\section{Resultados e discussões}

Essa seção explanará sobre os resultados obtidos nos testes executados no contexto desse trabalho. Traremos a análise do teste de desenvolvimento mental em geometria do estudante elaborado por Van Hiele (NASSER e SANT'ANNA, 2010) e os pré-testes e pós-testes elaborados pelos pesquisadores desse artigo. Tivemos a sorte de todos os estudantes da sala em estudo não faltarem durante a execução dos trabalhos, sendo assim, todos marcaram presença e participaram de todas as atividades.

A turma analisada é bastante heterogênea, onde cada estudante apresenta o seu tempo de raciocínio, compreensão e execução das atividades, ou seja, 
nessa turma existem diferentes ritmos de aprendizagem. Mesmo assim, com o empenho de todos, foi possível em alguns casos deduzirem sozinhos certas propriedades do quadrado. Vale ressaltar que foi necessário aproximadamente um mês para que os estudantes se acostumassem com a metodologia proposta no projeto, pois nunca haviam trabalhado desse modo até o momento.

Essa heterogeneidade também pode ser observada na idade, conforme o Quadro 1. Contudo, a Teoria de Van Hiele nos afirma que a aprendizagem está mais intimamente conectada à metodologia utilizada e não à idade do estudante.

Quadro 1 - Classe de idade dos estudantes da turma

\begin{tabular}{|c|c|c|}
\hline Idade & Estudantes & Proporção \\
\hline $15-18$ & 15 & $60 \%$ \\
\hline $19-22$ & 4 & $16 \%$ \\
\hline $23-26$ & 2 & $8 \%$ \\
\hline $27-30$ & 2 & $8 \%$ \\
\hline $31-34$ & 1 & $4 \%$ \\
\hline $35-38$ & 1 & $4 \%$ \\
\hline
\end{tabular}

Fonte: Dados da pesquisa.

$\mathrm{Na}$ turma, havia alguns estudantes com mais de 8 anos afastados da sala de aula, assim muitos relataram que não lembravam do conteúdo. Percebemos ainda que a maioria dos estudantes demonstrou entusiasmo com a atividade e aos poucos foram estimulados e ganhando autonomia em cada etapa da atividade e, desse modo, mostrando sua criatividade individualmente.

\subsection{0 teste de Van Hiele}

Nesse teste percebemos que a maioria dos estudantes não dominava o significado de palavras básicas para o estudo de geometria, palavras como paralelo, oposto, perpendicular, ângulo reto e vértice.

A tabulação dos níveis de desenvolvimento mental em geometria de cada estudante participante que fez o teste está descrita no Quadro 2, de acordo com os critérios a seguir:

- Nível 0 (Corresponde às questões 1 a 5): 
Para considerar que um sujeito atingiu o nível básico (0), é necessário que ele acerte, no mínimo, três das referidas questões.

- Nível 1 (Corresponde às questões 6 a 10):

Para considerar que um sujeito atingiu esse nível, é necessário que ele acerte, no mínimo, três das referidas questões.

- Nível 2 (Corresponde às questões 11 a 15)

Para considerar que um sujeito atingiu o nível 2, é necessário que ele acerte, no mínimo, três das referidas questões.

Sendo o nível anterior requisito para se atingir o nível atual, ou seja, para ser considerado de um nível é imprescindível ter atingido todos os níveis anteriores. O Quadro 2 apresenta o nível de desenvolvimento mental em geometria dos estudantes no início da pesquisa.

Quadro 2 - Nível de desenvolvimento mental em geometria dos estudantes no início da pesquisa

\begin{tabular}{|l|c|c|c|c|}
\hline $\begin{array}{c}\text { Sujeito da } \\
\text { Pesquisa }\end{array}$ & $\begin{array}{c}\text { Acertos no } \\
\text { Nível 0 }\end{array}$ & $\begin{array}{c}\text { Acertos no } \\
\text { Nível 1 }\end{array}$ & $\begin{array}{c}\text { Acertos no } \\
\text { Nível 2 }\end{array}$ & $\begin{array}{c}\text { Nível do } \\
\text { Estudante }\end{array}$ \\
\hline Estudante 01 & 3 & 2 & 1 & 0 \\
\hline Estudante 02 & 2 & 2 & 0 & - \\
\hline Estudante 03 & 3 & 1 & 0 & 0 \\
\hline Estudante 04 & 4 & 2 & 1 & 0 \\
\hline Estudante 05 & 2 & 1 & 2 & - \\
\hline Estudante 06 & 2 & 2 & 1 & 1 \\
\hline Estudante 07 & 4 & 3 & 0 & - \\
\hline Estudante 08 & 2 & 1 & 1 & 0 \\
\hline Estudante 09 & 4 & 2 & 0 & - \\
\hline Estudante 10 & 2 & 0 & 0 & 0 \\
\hline Estudante 11 & 0 & 0 & 1 & 1 \\
\hline Estudante 12 & 3 & 1 & 0 & 0 \\
\hline Estudante 13 & 4 & 3 & 0 & 0 \\
\hline Estudante 14 & 4 & 2 & 3 & 0 \\
\hline Estudante 15 & 3 & 1 & 0 & 1 \\
\hline Estudante 16 & 5 & 3 & 2 & - \\
\hline Estudante 17 & 3 & 2 & & - \\
\hline Estudante 18 & 3 & 3 & 0 & - \\
\hline Estudante 19 & 4 & 2 & 0 & - \\
\hline
\end{tabular}




\begin{tabular}{|l|l|l|l|l|}
\hline Estudante 20 & 2 & 2 & 1 & - \\
\hline Estudante 21 & 3 & 2 & 0 & 0 \\
\hline Estudante 22 & 1 & 1 & 0 & - \\
\hline Estudante 23 & 4 & 3 & 2 & 2 \\
\hline Estudante 24 & 3 & 2 & 0 & 0 \\
\hline Estudante 25 & 4 & 2 & 1 & 0 \\
\hline
\end{tabular}

Fonte: Dados da pesquisa.

Os dados do resultado obtido podem ser observados no Gráfico 1 logo abaixo onde estão relacionados a quantidade estudantes por níveis e suas proporções.

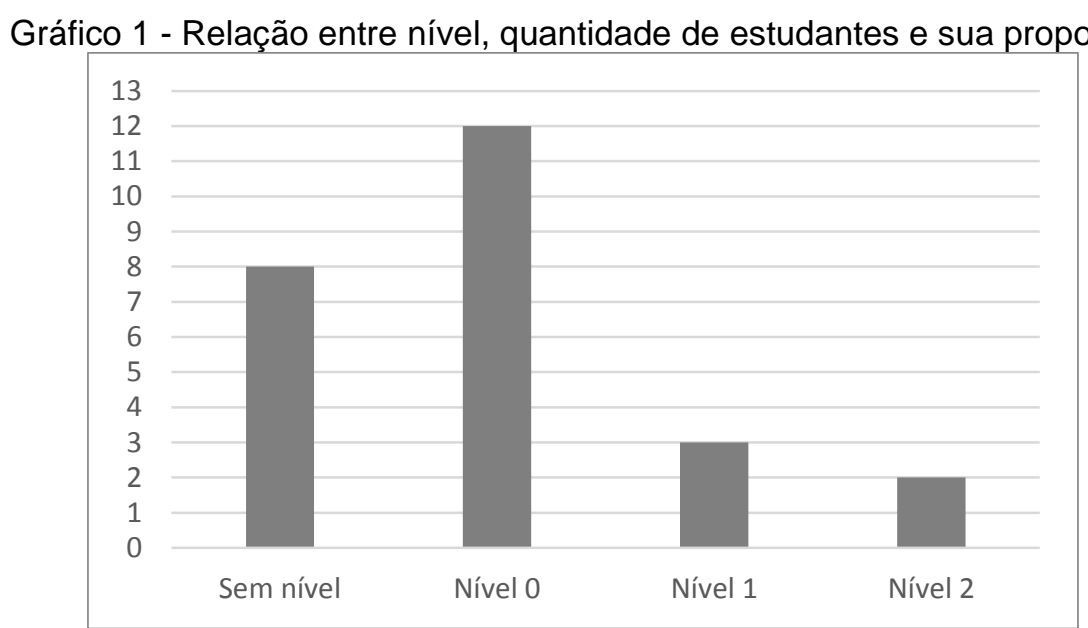

Fonte: Dados da pesquisa.

Com base no resultado obtido, podemos analisar os índices como interessantes para a elaboração das atividades do pré-teste e pós-teste, pois, apesar de um expressivo número de estudantes que nem sequer atingiram o Nível 0 , temos outros que se enquadram em algum nível e o desafio dos demais em sua aprendizagem. Ainda destacamos a quantidade de estudantes que não se enquadram nem no nível mínimo do modelo proposto, sendo que não conseguem nem reconhecer as formas geométricas (sem nível). 


\subsection{0 pré-teste e pós-teste}

O pré-teste servirá de base para comparação do antes e depois da intervenção pedagógica feita como citada anteriormente. Sendo realizado individualmente com cada participante e contando com a presença de todos.

Além da performance escrita nas resoluções dos testes, foram analisadas a participação ativa do estudante em cada atividade proposta e a linguagem usada nas argumentações orais que surgiram durante as atividades. Sendo importantíssimo destacar que seria impossível fazer uma análise do desenvolvimento dessas habilidades somente utilizando as respostas dos dois testes como referencial.

A observação contínua durante o processo de execução das atividades foi indispensável para que pudesse ser percebido e avaliado como critério de progresso de nível de pensamento geométrico. Ao aplicar o pré-teste, percebemos que o maior entrave para a execução das atividades foi o fato dos estudantes não terem tido uma aprendizagem significativa de conteúdos geométricos anteriores, seja por não terem sido trabalhados ou pelo fato de que esquecerem o conteúdo segundo relatos dos próprios estudantes.

Após o teste foi necessário exercitar e relembrar, a distância entre retas paralelas e perpendiculares, maneira de utilizar a régua, medir distância, traçar alturas, encontrar lados correspondentes entre figuras geométricas, ou seja, dar uma revisão dos conceitos e temos geométricos necessários para o bom andamento do projeto. $\mathrm{O}$ desempenho dos estudantes no pré-teste está disposto no Gráfico 2 que relaciona os acertos, erros e omissões por questão do pré-teste. 
Gráfico 2 - Quantidade de acertos, erros e omissões por questão do pré-teste

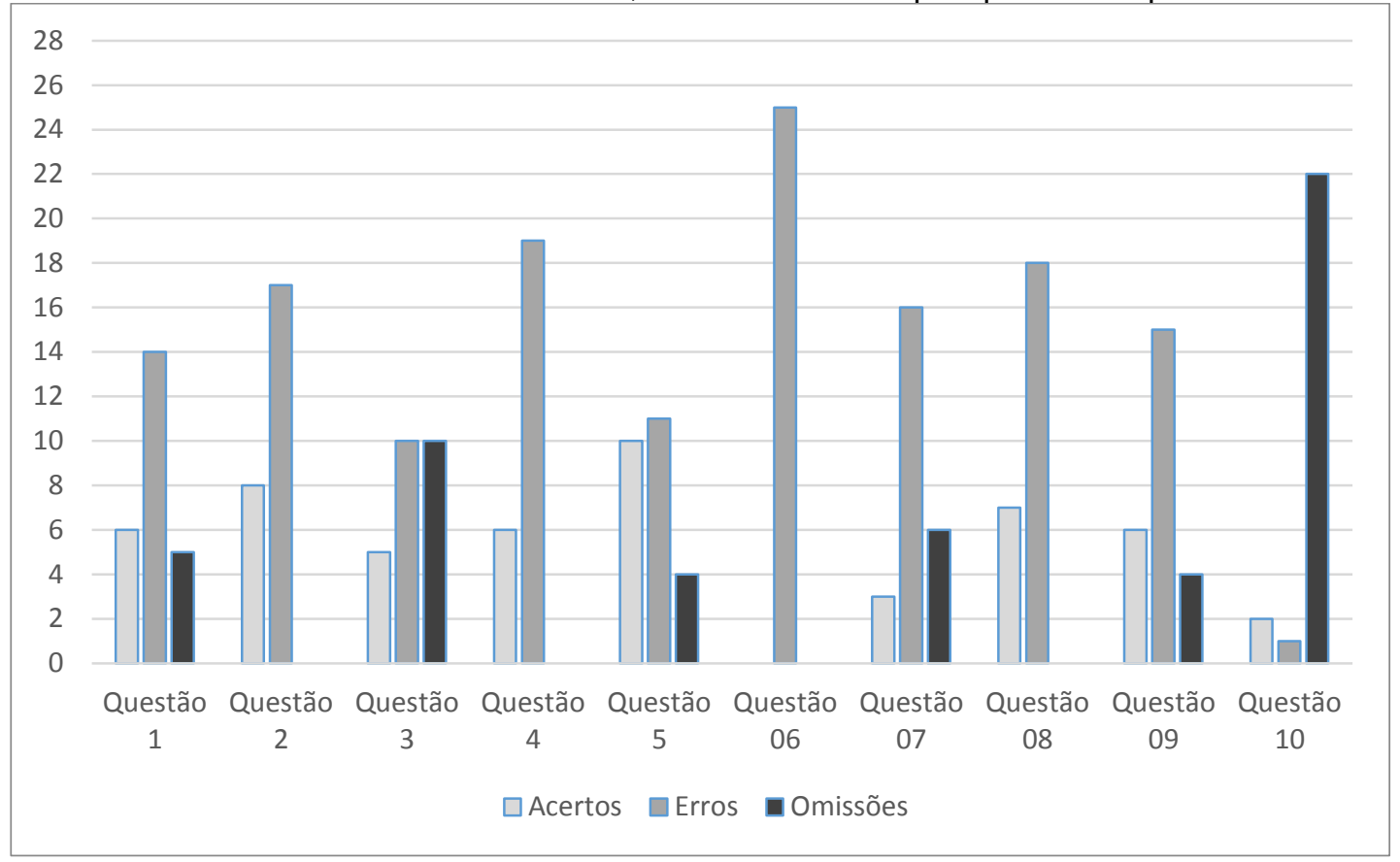

Fonte: Dados da pesquisa.

Podemos perceber que nas questões que lidam com a abstração tiveram um rendimento inferior às demais, sendo a questão 10 o destaque em abstenções que pode estar relacionada ao fato de se necessitar de uma comparação entre duas situações e eleger a situação mais viável diante das condições colocadas. Nas questões objetivas não foram obtidas omissões, devido à possibilidade de o estudante poder marcar uma resposta sem ter certeza do resultado.

O desempenho dos estudantes no pós-teste está disposto no Gráfico 3 que relaciona os acertos, erros e omissões por questão do pós-teste. 
Gráfico 3 - Quantidade de acertos, erros e omissões por questão do pós-teste

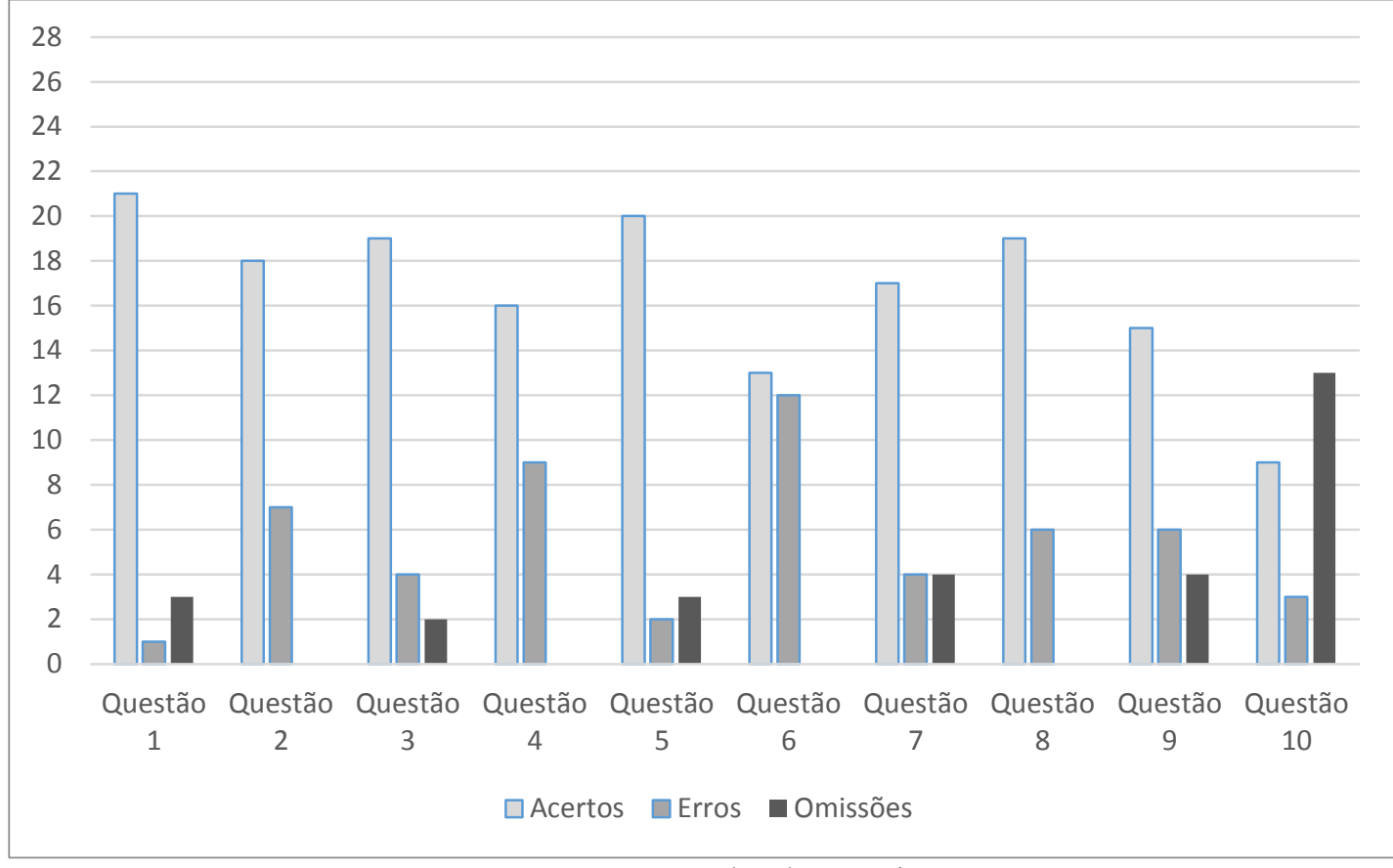

Fonte: Dados da pesquisa.

Podemos novamente perceber que as questões que lidam com a abstração permanecem tendo um rendimento inferior às demais, continuando a questão 10 o destaque em abstenções. No entanto, podemos ver melhora no desempenho de acertos e queda na omissão de respostas.

Com base nos Gráficos 2 e 3, nas questões 1, 3, 6 e 7, observa-se um aumento muito significativo na diferença do índice de acertos entre o pré e pósteste, sendo esse superior a $40 \%$. A questão 10 , por sua vez, foi a que ocorreu menos melhoria, mas também aumentou o índice de acertos, passando de 6\% para $28 \%$. Possivelmente essa diferença de desenvolvimento entre algumas questões se deva ao fato da necessidade de abstração e uma estratégia mais elaborada na questão 10.

Ainda com base nos referencias anteriores, quanto à omissão nas repostas o destaque foi a alteração nas questões 3 e 10 tendo melhora maior ou igual a $25 \%$ das respostas. Ressaltando que essa melhora não significa especificamente acertos, porém reflete na melhora da confiança para responder estas duas questões, pois somente quem tenta responder que tem possibilidade de acertar. 
No tocante às demais questões podemos perceber que as questões $1,5 \mathrm{e}$ 7 não obtiveram alteração acima de 7\% e as questões 2, 4, 6, 8 e 9 não sofreram alteração. Assim, podemos perceber a redução da omissão nas respostas dos testes, o que nos indica que os estudantes, no mínimo, tentaram a resolução do problema, ou seja, a atividade pode ser considerada, segundo Ausubel (2003), potencialmente significativa e desafiadora levando-os a interagir com o objeto de aprendizagem.

De acordo com todos esses critérios de avaliação, podemos relatar que os estudantes analisados demonstraram progresso no pós-teste em relação ao préteste. Houve aumentos expressivos na quantidade de acertos por questão, sendo importante ressaltar que, mesmo dentre os que obtiveram resultado abaixo da média, ocorreram progressos em alguns itens do teste e na linguagem geométrica que esses participantes passaram a utilizar.

\section{Considerações Finais}

A produção e aplicação das atividades sugeridas neste trabalho são um ensaio para melhorar a realidade do ensino e aprendizagem em Geometria, em especial o estudo de áreas. O principal objetivo foi alcançado, promover a produção dos estudantes com autonomia na construção do conhecimento geométrico de maneira que possibilite o aprendizado significativo sobre áreas de quadriláteros regulares, fazendo dele um ativo participativo na construção de conceitos matemáticos, valendo-se de linguagem apropriada e materiais concretos. Todas as atividades elaboradas respeitaram a ordem proposta pelos Van Hiele.

No estudo de caso concretizado na turma da $4^{\text {a }}$ etapa de EJA, pôde-se perceber o bom desempenho dos estudantes na resolução das atividades. Percebeu-se também a motivação e a curiosidade durante toda aula, além de uma maior interação entre eles. As discussões que surgiram e o seu comportamento mostraram que, para as circunstâncias que permearam essa 
pesquisa, o uso de técnicas que utilizam as tecnologias e materiais manipuláveis obtém sucesso no que se refere ao ensino de geometria. Desse modo, o modelo de Van Hiele foi fundamental para desenvolvimento do conhecimento geométrico, pois os estudantes conseguiram explorar propriedades geométricas, contribuindo de forma expressiva para o processo de ensino e aprendizagem de conceitos geométricos relacionados ao conteúdo de áreas quadriláteros regulares.

Vale destacar que as conclusões apresentadas nesse trabalho, não são únicas e nem definitivas, como é típico em pesquisa qualitativa. Essa proposta utilizou-se a malha quadriculada como recurso pedagógico para obtenção do conceito de área e para a dedução das fórmulas, pois essa ferramenta favoreceu a visualização de propriedades. Nesse contexto, propõe-se também o uso de materiais concretos que fazem referência ao cotidiano do estudante, que foram embalagens de produtos que se encaixam no molde da pesquisa.

Espera-se que este trabalho possa destacar a importância de abordagens inovadoras para a aquisição de conceitos matemáticos. Mais especificamente, que possa contribuir para o processo de ensino e aprendizagem de áreas de figuras planas. Que no caso desse trabalho, foi o método de Van Hiele.

\section{Referências}

AUSUBEL, David P. Aquisição e retenção de conhecimentos: uma perspectiva cognitiva. Lisboa: Plátano, 2003.

CROWLEY, Mary L.. O modelo Van Hiele de desenvolvimento do pensamento geométrico. In: LINDQUIST, Mary; SHULTE, Albert P. Aprendendo e Ensinando Geometria. Tradução de Hygino H. Domingues. São Paulo: Atual Editora, 1994.

GIL, Antônio Carlos. Como elaborar projetos de pesquisa. 4ª . ed. São Paulo: Atlas, 2002.

LORENZATO, Sergio. O laboratório de ensino de matemática na formação de professores. [S.I.]: Autores Associados, 2009.

MATOS, José M.; SERRAZINA, Maria de Lurdes. Didática da matemática. Lisboa: Universidade Aberta, 1996. 
MORAES, Maritza. C. et al. As tecnologias digitais na geometria do cotidiano: o (re)pensar da prática docente. Prisma.com, Porto, n. 28, 2015. 145-166.

NASSER, Lílian.; SANT'ANNA, Neide. Geometria segundo a teoria de van Hiele. Rio de Janeiro: Projeto Fundão IM/UFRJ, 2010.

NEVES, Eduardo. B.; DOMINGUES, Clayton. A. Manual da Metodologia da Pesquisa Científica. Rio de Janeiro: ESAO, 2007.

SOUZA, Carla. F. Estudo de quadriláteros, reflexões e rotações no plano, segundo a teoria de van Hiele: uma experiência com alunos do $9^{\circ}$ ano do ensino fundamental. Seropédica: Dissertação de Mestrado - UFRRJ, PROFMAT, 2014. 